\title{
Recycling the Previous Local Flap in Patients for Sequential Defects - A Case Report and its Literature Review \\ Georgia-Alexandra Spyropoulou' ${ }^{1}$, Hsiang-Shun Shih ${ }^{2}$, Kuan-Ming Feng ${ }^{2}$ and Seng-Feng Jeng ${ }^{2}$
}

${ }^{1}$ Department of Plastic Surgery, Aristotle University of Thessaloniki, "Papageorgiou" General Hospital, Periferiaki Odos N. Efkarpia, Thessaloniki, Greece

${ }^{2}$ Department of Plastic and Reconstructive Surgery, E-Da hospital, I-Shou University, Kaohsiung City, Taiwan

\begin{abstract}
Background: Flap recycling is a relatively new technique that enables Plastic Surgeons to use part or all of flaps that have been utilized to cover a defect, for the reconstruction of a new consequent defect adjacent to the first one. We present a series of patients where recycled flaps have been raised from previous local pedicled flaps to cover adjacent sequential defects.

Materials and methods: From November 2013 to November 2015 we performed 12 recycled flaps to 12 patients (9 men and 3 women). The mean age of the patients was 55.9 years (range, 21 to 78 years). All 12 flaps were raised from previous local pedicled flaps. The mean time between the primary reconstruction and secondary recycle procedure was 59.5 months (range, 12 to 144 months).

Results: The mean size of the recycled flap was $54.4 \mathrm{~cm}^{2}$. Three flaps were raised as perforator flaps with complete pedicle skeletonization, two were raised as random pattern flaps and the rest were raised as axial pattern flaps without pedicle skeletonization. All recycled flaps survived completely and all donor sites were closed directly.

Conclusion: Local flap recycling from previous flaps can be a very attractive technique, especially in cases of nose and foot defects as there is deficiency of tissues that can be used as local flaps and in cases of neuropathetic disorders, as diabetes mellitus or pressure sores where the patients are repeatedly operated for recurrent ulcers. Thus, the patient could be spared of additional donor sites and save precious backup flaps for later use.
\end{abstract}

Keywords: Flap recycling; Local flap; Perforator flap

\section{Introduction}

The concept of recycling of flaps is a relatively new and attractive model that enables Plastic Surgeons to reuse flaps that have already been transferred for coverage of neighboring defects. This method offers the advantage that additional donor sites are spared [1] published a series of 60 patients where recycled flaps were raised mainly from previous free flaps. They also described the indications and presented a classification of recycled flaps:

- Type 1 recycle flap is raised simply as a random pattern flap.

- Type 2 recycle flap is raised as a pedicled perforator flap without pedicle skeletonization. The pedicle is identified pre-operatively with hand held Doppler. The flap is mobilized intraoperatively along the vessel axis.

- Finally, Type 3 recycle flap is dissected as a pedicled perforator flap but with pedicle skeletonization. The flap can then be rotated 180 degrees as a propeller flap, advanced, transposed, interpolated or even transferred as a free flap. In this paper we present a series of patients where recycled flaps have been raised from previous local pedicled flaps to cover adjacent sequential defects.

\section{Patients and Methods}

From November 2013 to November 2015 we performed 12 recycled flaps to 12 patients ( 9 men and 3 women). We reviewed the files of the patients and documented the age, etiology of the defect, primary reconstructive procedure, time interval between primary and recycle flap, indication and type of recycle flap, the recycle flap size, the pedicle length (if the recycled flap was pedicled) and the complications. The mean age of the patients was 55.9 years (range, 21 to 78 years). All 12 flaps were raised from previous local pedicled flaps. The principles for raising the flaps were the same as for any local flap: placement of the flap axis along the skin relaxation lines, design of the flap to at least match the defect's dimensions and use of the pinch test to assess direct closure of the donor site. When the defect was created, the handheld Doppler device was used to detect the site of perforators and the flap was designed in order to include at least one perforator. As a rule of thumb, when the distance of the selected perforator to the proximal margin of defect measured along the flap movement axis was shorter than the defect's diameter along the flap movement axis, an axial pattern flap could be advanced into the defect. Otherwise, if the aforementioned distance was larger, the flap should be dissected as a perforator flap and transposed or used as a propeller flap into the defect. The mean time between the primary reconstruction and secondary recycle procedure was 59.5 months (range, 12 to 144 months). The details of all the 12 cases and patients are summarized in Table 1. In this case report we mention three such representative cases of the 12 cases mentioned.

\section{Representative Case presentation of cases 6, 7 and 8}

\section{Case 6}

A 76-years-old female patient has been operated in the past with pedicle forehead flap for a nose defect after BCC excision. Five years

*Corresponding author: Georgia-Alexandra Spyropoulou, Assistant Professor in the Department of Plastic Surgery, Aristotle University of Thessaloniki, "Papageorgiou" General Hospital, Periferiaki Odos N. Efkarpia, 56403, Thessaloniki, Greece, Tel: 0030-6938-415488/ 0030-2313-323888; E-mail: gspyropoulou@hotmail.com

Received April 19, 2018; Accepted July 14, 2018; Published July 17, 2018

Citation: Spyropoulou GA, Shih HS, Feng KM, Jeng SF (2018) Recycling the Previous Local Flap in Patients for Sequential Defects - A Case Report and its Literature Review. J Trauma Treat 7: 426. doi: 10.4172/2167-1222.1000426

Copyright: @ 2018 Spyropoulou GA, et al. This is an open-access article distributed under the terms of the Creative Commons Attribution License, which permits unrestricted use, distribution, and reproduction in any medium, provided the original author and source are credited. 
postoperatively, she presented with a new primary BCC at the tip of the nose adjacent to the previous reconstruction (Figure 1a). The lesion was excised widely with free margin which resulted in $2 \times 2 \mathrm{~cm}$ defect. When the defect was prepared, the handheld Doppler device was used to detect the site of perforators and the flap was designed in order to include the supratrochlear perforator of the previous flap. A $4 \times 4$ $\mathrm{cm}$ recycle flap was elevatedas perforator flap with complete pedicle skeletonization. The length of the pedicle was $2 \mathrm{~cm}$ (Figure $1 \mathrm{~b}$ ). The flap (type 3a) was advanced to cover the nasal tip defect without tension. The donor site was closed directly and the flap survived completely (Figure 1c). Both the patient and Surgeon judged the long term result (2 years post-operatively) as very satisfactory (Figure $1 \mathrm{~d}$ ).

\section{Case 7}

A 56-year-old male presented with facial BCC on the right malar area adjacent to the site that was previously reconstructed with a nasolabial flap (Figures 2a-2c). The second primary BCC (Figure 2d) presented 1.5 years after the first operation where the local flap was used to reconstruct a defect due to a previously excised BCC. Two perforators were located with the Doppler on the nasolabial flap (Figure 2e). The flap $3.5 \times 2.5 \mathrm{~cm}$ in size was raised, based on one of the perforators (Figure 2f) as an axial pattern flap without pedicle skeletonization (type 2 recycle flap). The donor site was closed directly and the flap survived completely (Figure $2 \mathrm{~g}$ ).

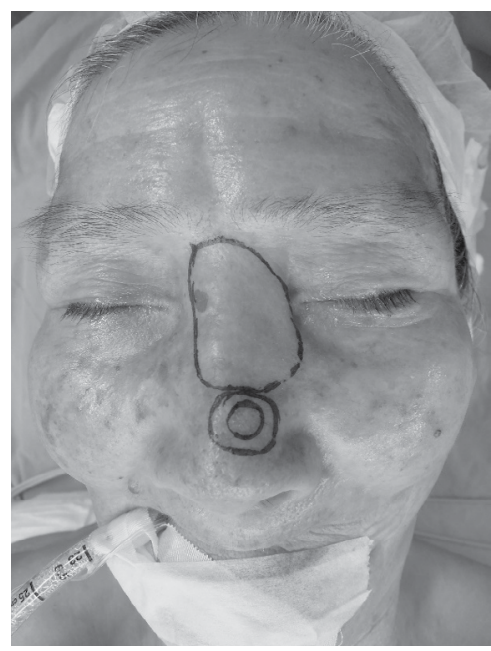

Figure 1a: A 76-years-old female patient with second primary BCC at the tip of the nose adjacent to the previous reconstruction with pedicle forehead flap. The supra-trochlear perforator is marked with hand-held Doppler at the previous flap.

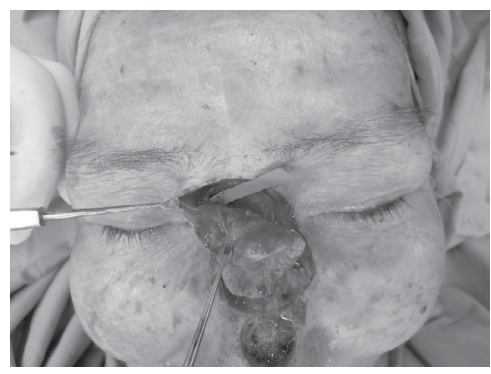

Figure 1b: The defect resulting from wide excision of the lesion was $2 \times 2 \mathrm{~cm}$ wide. A $4 \times 4$ recycle flap is elevated as perforator flap on the supratrochlear perforator with complete pedicle skeletonization. The length of the pedicle was $2 \mathrm{~cm}$.

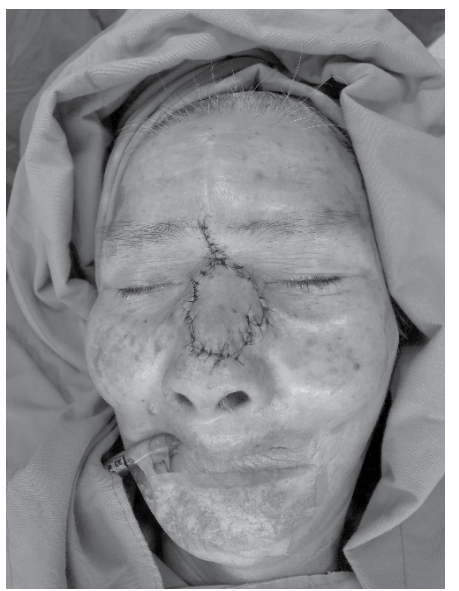

Figure 1c: The flap was advanced to cover the nasal tip defect without tension The donor site was closed directly and the flap survived completely.

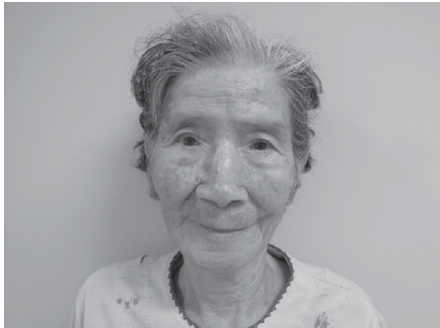

Figure 1d: Both the patient and Surgeon judged the long term result (2 years post-operatively) as very satisfactory.

\section{Case 8}

A 47-year-old male had undergone reversed medial plantar flap reconstruction for a right distal sole diabetic ulcer (Figures 3a-3c). Two years postoperatively, the patient presented with a recurrent diabetes mellitus ulcer adjacent to the previous reconstruction $3 \times 2 \mathrm{~cm}$ in size (Figure 3d). Preoperative Doppler ultrasound detected the perforator from the previous reversed medial plantar artery. A flap $5 \times 5 \mathrm{~cm}$ in size was raised and recycled as an axial pattern flap without pedicle skeletonization (Type 2 recycle flap) to cover the defect (Figure 3e). The donor site was closed directly and there was no recurrence at 12 month follow up (Figure 3f).

\section{Results}

The etiology of the initial defect was oral cancer in 2 cases, head and neck skin cancer in 3 cases, ischial pressure sore in 4 cases, breast cancer in 1 case and 2 foot ulcers. Indications for the recycle flap were: recurrent pressure sore in 4 cases, cancer recurrence in 2 cases, recurrent ulcer in 3 cases, lower lip contracture in 1 case and new primary face BCC (basal cell carcinoma) in 2 cases. The mean size of the recycled flap was $54.4 \mathrm{~cm}^{2}$. Three flaps were raised as perforator flaps with complete pedicle skeletonization based on perforators from the previous reconstruction (type 3), two were raised as random pattern flaps (type 1) and the rest were raised as axial pattern flaps without pedicle skeletonization (type 2 pedicle perforator flap) [1]. All recycled flaps survived completely and all donor sites were closed directly. The operations were performed under general anesthesia. There was one case of wound infection that settled with antibiotics. 
Citation: Spyropoulou GA, Shih HS, Feng KM, Jeng SF (2018) Recycling the Previous Local Flap in Patients for Sequential Defects - A Case Report and its Literature Review. J Trauma Treat 7: 426. doi: 10.4172/2167-1222.1000426

Page 3 of 5

\begin{tabular}{|c|c|c|c|c|c|c|c|c|}
\hline No & Sex/age & Etiology & $\begin{array}{l}\text { Previous } \\
\text { procedure }\end{array}$ & \begin{tabular}{|c|} 
Time \\
interval
\end{tabular} & Indication and subsequent procedure & Flap size & Pedicle length & Complications \\
\hline 1 & Male/28 & $\begin{array}{l}\text { Right ischial } \\
\text { Pressure sore }\end{array}$ & $\begin{array}{c}\text { Posterior thigh } \\
\text { flap }\end{array}$ & 4 years & Recurrent pressure sore Axial pattern flap & $10 \times 4 \mathrm{~cm}$ & $\mathrm{n} / \mathrm{a}$ & None \\
\hline 2 & Male/70 & Right buccal cancer & $\begin{array}{c}\text { Pectoralis major } \\
\text { MC flap }\end{array}$ & 3 years & Cancer recurrence Random turnover flap & $8 \times 4 \mathrm{~cm}$ & $\mathrm{n} / \mathrm{a}$ & None \\
\hline 3 & Male/76 & Right face $\mathrm{BCC}$ & Nasolabial flap & 10 years & Cancer recurrence Random pattern flap & $4 \times 2 \mathrm{~cm}$ & $\mathrm{n} / \mathrm{a}$ & None \\
\hline 4 & Female/74 & Left breast cancer & $\begin{array}{l}\text { Pedicle vertical } \\
\text { RA MC Flap }\end{array}$ & 10 years & Recurrent chronic ulcer Pedicle perforator flap & $15 \times 9 \mathrm{~cm}$ & $4 \mathrm{~cm}$ & None \\
\hline 5 & Male/37 & $\begin{array}{l}\text { Right ischial } \\
\text { Pressure sore }\end{array}$ & $\begin{array}{l}\text { Posterior thigh } \\
\quad \text { flap }\end{array}$ & 4 years & $\begin{array}{l}\text { Recurrent pressure sore Pedicle perforator } \\
\text { flap }\end{array}$ & $14 \times 10 \mathrm{~cm}$ & $3 \mathrm{~cm}$ & None \\
\hline 6 & Female/76 & Nose BCC & $\begin{array}{c}\text { Pedicle } \\
\text { forehead flap }\end{array}$ & 5 years & Nasal tip BCC Pedicle perforator flap & $4 \times 4 \mathrm{~cm}$ & $2 \mathrm{~cm}$ & None \\
\hline 7 & Male/56 & Face BCC & Nasolabial flap & 1.5 years & Right cheek BCC Axial pattern flap & $3.5 \times 2.5 \mathrm{~cm}$ & $\mathrm{n} / \mathrm{a}$ & None \\
\hline 8 & Male/47 & $\begin{array}{c}\text { Right distal sole DM } \\
\text { ulcer }\end{array}$ & Instep flap & 2 years & Recurrent DM ulcer Axial pattern flap & $5 \times 5 \mathrm{~cm}$ & $\mathrm{n} / \mathrm{a}$ & None \\
\hline 9 & Male/54 & $\begin{array}{l}\text { Right ischial pressure } \\
\text { sore }\end{array}$ & $\begin{array}{l}\text { Pedicle SG MC } \\
\text { flap }\end{array}$ & 2 years & Recurrent pressure sore Axial pattern flap & $10 \times 8 \mathrm{~cm}$ & $\mathrm{n} / \mathrm{a}$ & None \\
\hline 10 & Male/53 & $\begin{array}{l}\text { Left ischial } \\
\text { pressure sore }\end{array}$ & $\begin{array}{c}\text { Posterior thigh } \\
\text { flap }\end{array}$ & 5 years & Recurrent pressure sore Axial pattern flap & $15 \times 10 \mathrm{~cm}$ & $\mathrm{n} / \mathrm{a}$ & Wound infection \\
\hline 11 & Male/60 & Left lower gum cancer & Nasolabial flap & 1 year & Lower lip contracture Axial pattern flap & $4 \times 3 \mathrm{~cm}$ & $\mathrm{n} / \mathrm{a}$ & None \\
\hline 12 & Female/40 & $\begin{array}{l}\text { Left big toe radiation } \\
\text { ulcer }\end{array}$ & $\begin{array}{l}\text { Second hemi- } \\
\text { pulp flap }\end{array}$ & 12 years & Recurrent ulcer Axial pattern flap & $3 \times 2 \mathrm{~cm}$ & $\mathrm{n} / \mathrm{a}$ & None \\
\hline
\end{tabular}

BCC: Basal Cell Carcinoma, DM: Diabetes Mellitus RA: Rectus Abdominis, SG: Superior Gluteal, MC: Myocutaneous, N/A: Not Applicable

Table 1: A detailed case representation of all the 12 cases mentioned.

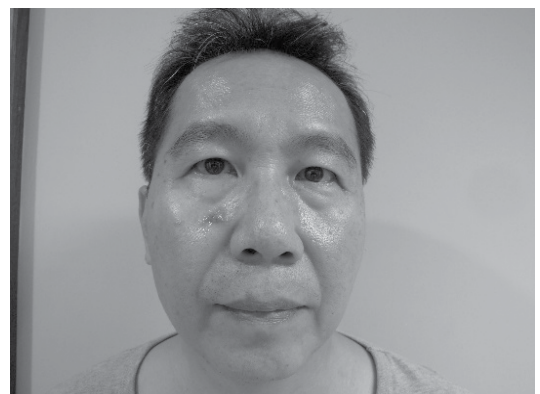

(a)

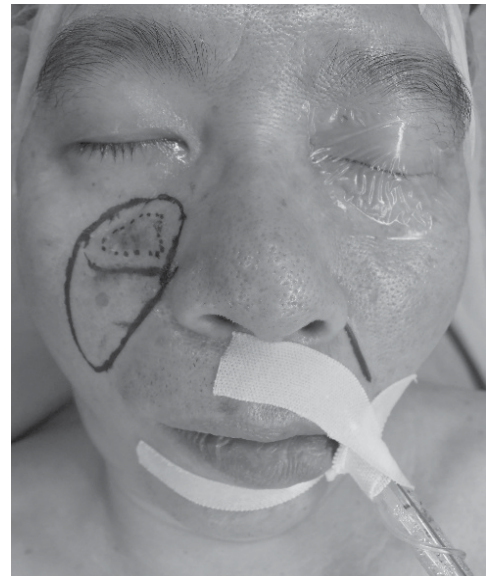

(b)

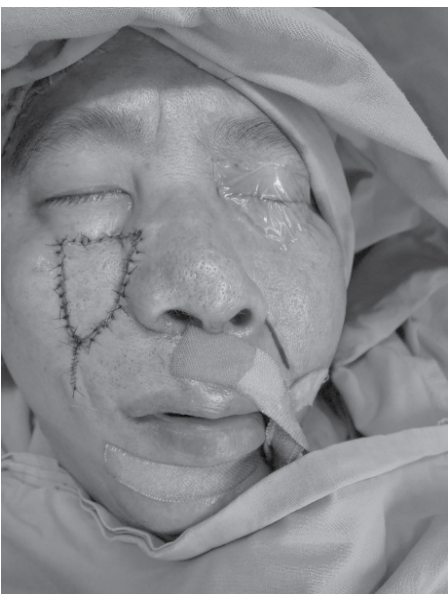

(c)

Figure 2 (a-c): A 54-years-old male with primary BCC on the right malar area that was reconstructed with a nasolabial flap.

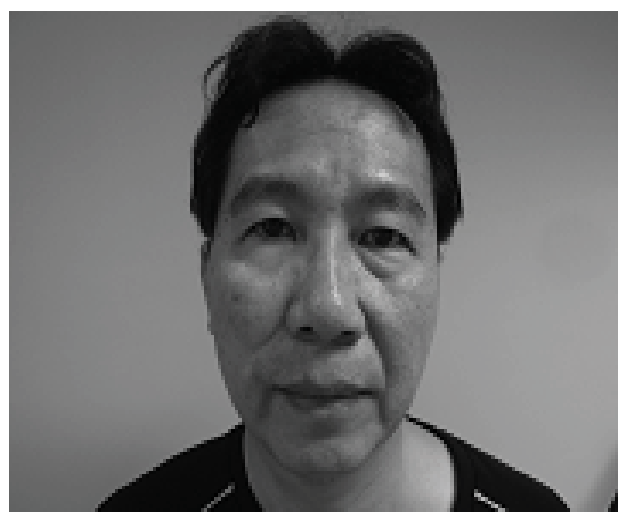

Figure 2d: One and a half year after the initial procedure the patient presented with a second primary BCC adjacent to the first reconstruction.

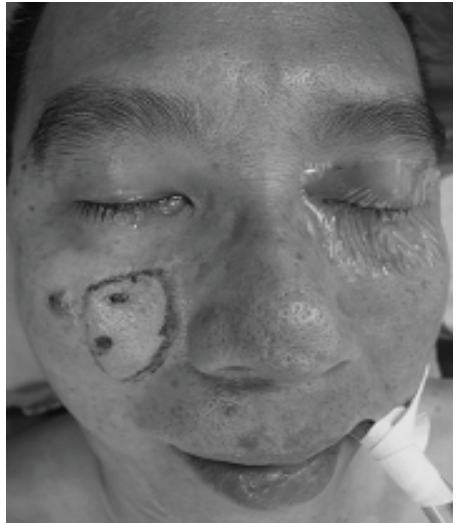

Figure 2e: Two perforators were located with the handheld Doppler on the nasolabial flap. 
Citation: Spyropoulou GA, Shih HS, Feng KM, Jeng SF (2018) Recycling the Previous Local Flap in Patients for Sequential Defects - A Case Report and its Literature Review. J Trauma Treat 7: 426. doi: 10.4172/2167-1222.1000426

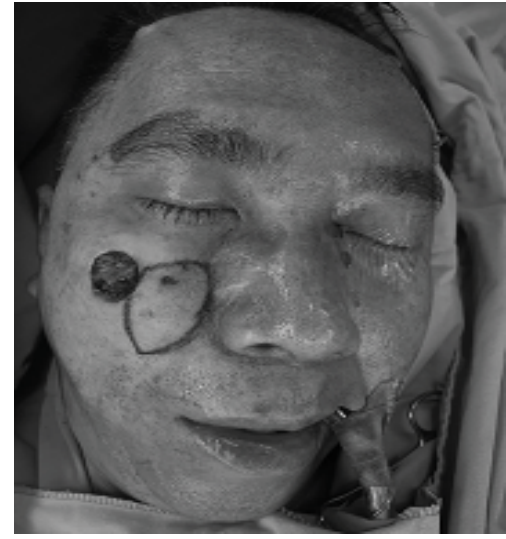

Figure 2f: A $3.5 \times 2.5 \mathrm{~cm}$ flap was raised, based on one of the perforators as an axial pattern flap without pedicle skeletonization.

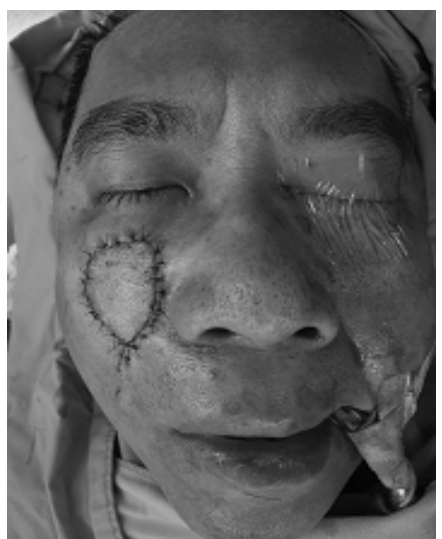

Figure 2g: The donor site was closed directly and the flap survived completely.

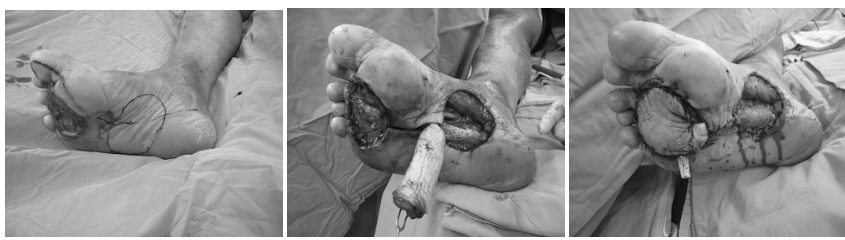

Figure 3 (a-c): A 47-year-old male had undergone reversed medial plantar flap reconstruction for a right distal sole diabetic ulcer.

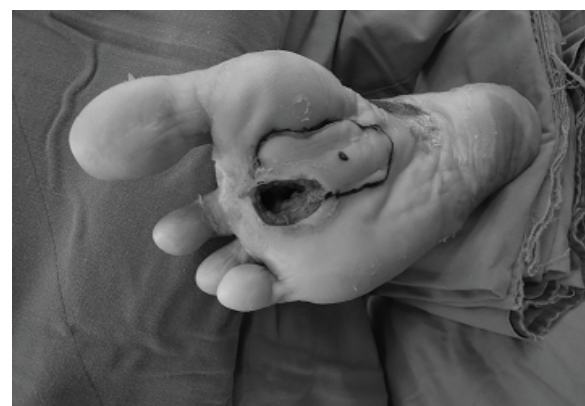

Figure 3d: Two years post-operatively, the patient presented with a recurrent diabetes mellitus ulcer adjacent to the previous reconstruction. The perforator from the previous reversed medial plantar artery flap was located with handheld Doppler.

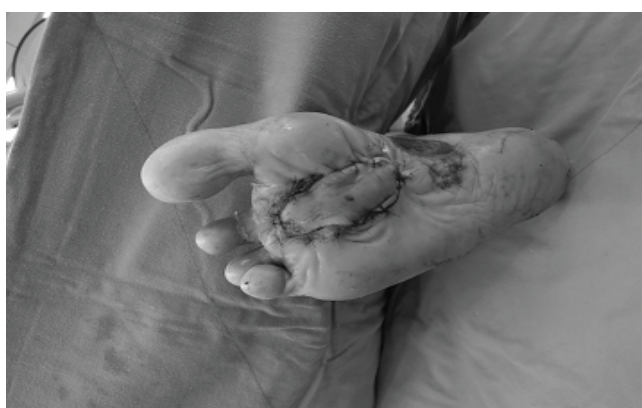

Figure 3e: A recycled flap $5 \times 5 \mathrm{~cm}$ in size was raisedas an axial pattern flap without pedicle skeletonization to cover the defect.

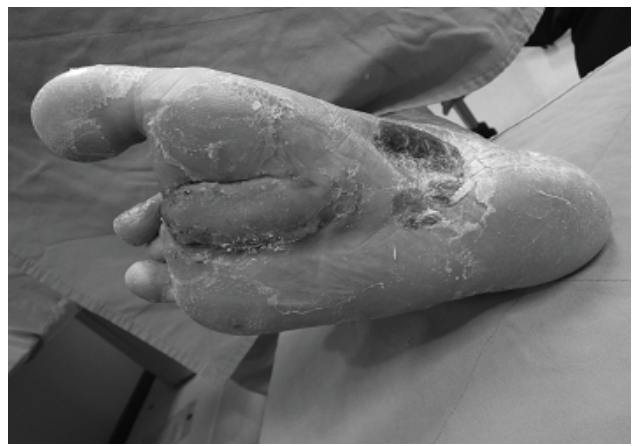

Figure 3f: The donor site was closed directly and there was no recurrence at 12 months follow up.

\section{Discussion}

Flap recycling has been first described in 2008 when Mun et al. reused a previously transferred perforator flap in the reconstruction of a subsequent tibial defect [2]. Since then, there have been few reports of recycled flaps: Tan et al. described the recycling of a groin flap from the left wrist of an 8 year old girl that had both hands amputated from meningococcal septicaemia, for reconstruction of a flexion contracture at her right wrist [3]. Hallock used a perforator flap from breast reconstructed with DIEP (deep inferior epigastric artery perforator) flap for the secondary reconstruction of the contralateral breast where the previous DIEP flap had failed [4]. Feng et al. published a series of 13 recycled perforator flaps [5] and Kurita reported 3 cases of recycling temporalis muscle flaps that had been used initially for smile reconstruction and were transferred for eyelid closure consequently [6]. Finally, Sadigh et al. reported a series of 60 patients along with a useful classification of recycled flap 1 [1].

Most of these papers refer to perforator flaps that were dissected from the initial flap and transferred as either pedicled or free to the secondary recipient site [2-6]. However, local defects adjacent to the previous reconstruction can usually be covered with random and axial pattern flaps as in most of our cases. In recycled perforator flaps dissection of the pedicle can be demanding, especially, in cases of previous irradiation of the flap 1 . However, in random and axial pattern flaps dissection is safe and fast. Indeed, all our flaps survived completely. Random pattern flaps do not even require Doppler identification of the pedicle preoperatively. It must be stressed that in these cases we did not need a great degree of flap mobilization. Nevertheless, if a greater degree of flap mobilization is required as in cases 4,5 and 6 , then, dissection of the flap as perforator flap is mandatory [1]. The flap can consequently 
be advanced, transposed or used as a propeller flap to cover the defect. Dissection of recycle pedicle perforator flaps from previous flaps (cases 4,5 and 6) follows the free-style technique as described by Wei et al. [7].

The obvious benefit of flap recycling is that the need for a second donor site is eliminated. Moreover, all the donor sites could be closed primarily and the final results are satisfying both functionally and cosmetically. The possible disadvantages of recycled flaps include the possibility of inaccurately mapping the location of a skin vessel and the inability to predict the pedicle length, as well as injury to the delicate vessel during the dissection. Because of these potential disadvantages, one should always have a back-up plan. We suggested that more than one flap is planned. During the dissection, the flap can be redesigned depending on the operative finding. If a more reliable perforator can be found, one can easily shift the skin island over that vessel instead. If the surgeon cannot find a sizable perforator or injures the pedicle of the designed free-style flap, the surgeon can revert to the backup procedures following the reconstructive ladder. Another disadvantage is that the time of the operation is prolonged and there is the need for general anesthesia. Indeed, in cases where local recycled flaps have been used (Cases 6 and 7) the defect could be covered with another local flap, a quicker procedure that could be performed under local anesthetic. Nonetheless, with the recycling flap technique, the amount of scarring is reduced and this could be an additional gain to the patient. Especially, in cases of neuropathetic disorders, as diabetes mellitus or pressure sores where the patients are repeatedly operated for recurrent ulcers (Cases 1, 5, 8, 9, 10) flap recycling could be a very useful method and the same flap could be used twice or, why not thrice. Thus, the patient could be spared of additional donor sites and save precious backup flaps for later use.

\section{Conclusion}

According to our review of the literature there is only one other paper where prior perforator flaps have been used as local flap donor sites for recycled flaps confined to the head and neck area [8]. In this study, we describe 12 cases where local flaps have been raised from previous pedicled flaps for the coverage of adjacent defects in head and neck, torso and foot. Especially, in foot area local flap recycling from previous reverse instep flaps can be a very attractive technique, as there is deficiency of tissues that can be used as local flaps $[9,10]$. We are currently working on presenting a larger series of recycled local flaps from prior flaps that have been used for the coverage of foot and ankle defects.

\section{References}

1. Sadigh PL, Hsieh CH, Feng GM, Shih HS, Jeng SF, et al. (2015) A "green" approach to secondary reconstruction: The concept of the recycle flap and a classification. Plast Reconstr Surg 135: e401-e412.

2. Mun GH (2008) Recycled free septocutaneous perforator flap. Ann Plast Surg 60: $37-40$.

3. Tan J, Kay S, Bourke G (2011) Two for the price of one: Recycling a free flap J Plast Reconstr Aesthet Surg 64: 1702-1704.

4. Hallock G (2012) Sequential bilateral breast reconstruction using a split solitary deep inferior epigastric artery perforator flap. J Reconstr Microsurg 28: 573-575.

5. Feng KM,Hsieh CH, Jeng SF (2013) Free-style puzzle flap: The concept of recycling a perforator flap. Plast Reconstr Surg 131: 258-263.

6. Kurita M, Takushima A, Shiraishi T, Kinoshita M, Ozaki M, et al. (2013) Recycle of temporal muscle in combination with free muscle transfer in the treatment of facial paralysis. J Plast Reconstr Aesthet Surg 66: 991-995.

7. Wei FC, Mardini S (2004) Free-style free flaps. Plast Reconstr Surg 114 910-916.

8. Kokkoli E, Shih HS, Spyropoulou GA, Jeng SF (2016) Local freestyle perforatorflaps in head and neckreconstruction: An update and a usefulclassification. Plast Reconstr Surg 137: 1863-1874.

9. Lee S, Kim MB, Lee YH, Baek JK, Baek GH, et al. (2015) Distally based abductor hallucisadipomuscular flap for forefoot plantar reconstruction. Ann Plast Surg 75: 319-322.

10. Valentin G, Rodica M, Manuel L (2014) Plantar flaps based on perforators of the plantar metatarsal/common digital arteries. J Reconstr Microsurg 30 469-474. 